\title{
Word order in wh-questions in a North Norwegian dialect: some evidence from an acquisition study
}

\section{Marit Richardsen Westergaard}

\begin{abstract}
While standard Norwegian is a V2 language, some Norwegian dialects exhibit V3 in certain types of $w h$-questions. In some previous work on the Troms $\varnothing$ dialect, V3 has been considered the 'true' dialect and speakers' acceptance of V2 simply a result of the influence from the standard language. Based on child and adult data from a study of the acquisition of word order in the Troms $\varnothing$ dialect, I will argue that both V2 and V3 orders are part of the dialect - used by adult speakers and acquired (more or less) simultaneously by children. It will further be argued that the choice between the two depends on the information structure of the sentence, more specifically, on the interpretation of the subject as given or new information.
\end{abstract}

Keywords child language acquisition, information structure, Norwegian, syntax, word order

Marit Richardsen Westergaard, Department of English, University of Troms $\phi$, N-9037 Troms $\phi$,

Norway. E-mail: Marit.R.Westergaard@hum.uit.no

\section{INTRODUCTION}

Norwegian is a verb-second (V2) language with the verb in second position in all main clauses, standardly assumed to be the result of verb movement to C (see Vikner 1995). However, certain Norwegian dialects allow wh-questions without verb movement. In the dialect of Troms $\varnothing$, described by e.g. Taraldsen (1986) and Rice \& Svenonius (1998), the question words korfor, korsen and katti ('why', 'how' and 'when') always trigger verb movement, as illustrated by the V2 word order in the sentences in (1). In contrast, verb movement is not required after the monosyllabic wh-words ka, kem and kor ('what', 'who' and 'where'), yielding the V3 order seen in (2).

(1) a. Korfor gikk ho?/*Korfor ho gikk? why went she why she went

'Why did she go?' 
b. Korsen har ungan det?/*Korsen ungan har det? how have kids-DEF it how kids-DEF have it 'How are the kids doing?'

c. Katti kommer du?/*Katti du kommer? when come you when you come 'When are you coming?'

(2) a. Ka legen sa? what doctor-DEF said 'What did the doctor say?'

b. Kor du bor? where you live 'Where do you live?'

c. Kem den nye læreren er? who the new teacher-DEF is 'Who is the new teacher?'

However, the wh-questions with the monosyllabic question words in (2) are also considered grammatical by speakers of this dialect when verb movement has applied, as shown in (3) below. In addition, there does not seem to be any significant difference in meaning between the two word orders when the sentences are uttered in isolation (but see section 2.3 below).

(3) a. Ka sa legen?

what said doctor-DEF

'What did the doctor say?'

b. Kor bor du?

where live you

'Where do you live?'

c. Kem er den nye læreren?

who is the new teacher-DEF

'Who is the new teacher?'

True optionality in syntax may be undesirable in certain theoretical frameworks, and speakers' acceptance of both word orders in this construction has been explained as dialect mixture, e.g. by Taraldsen (1986): the V3 version is the 'true' dialect and the V2 order is a result of interference from the standard language. Both Nordgård (1985) and Taraldsen (1986) assume that V2 word order is ungrammatical in Northern dialects of Norwegian, and Taraldsen argues (p. 25) that the fact that speakers will occasionally "use and accept [V2] should be attributed to ... most dialect speakers [being] "bilingual"'. Rice \& Svenonius (1998), who also provide an analysis of the data which excludes sentences like those in (3), claim that their 'own observation is 
that although informants accept [V2] ... when it is suggested, they almost invariably use the non-V2 order in contexts of neutral intonation' (p. 3). If this is the case, then one would expect children growing up in this area to acquire the word order of the dialect first and only later become influenced by the standard language. ${ }^{1}$ It would also be expected that to the extent that dialect speakers PRODUCE V2 word order at all in these $w h$-questions, this should be the result of relatively random choices made by the speakers and not be subject to any syntactic or pragmatic constraints (except possibly linked to formal style).

In a study of the acquisition of V2 word order in Norwegian, I have investigated data (collected mainly by research fellow Merete Anderssen) from three children in Troms $\varnothing$, from the age of approximately 1;9 to 3. Based on these data and on an investigation of some of the adult speech in the material, I will argue in this paper that the V3 word order in (2) as well as the V2 sentences in (3) are part of the Troms $\varnothing$ dialect: both word orders are used regularly by adult speakers and, moreover, the choice between the two word orders is not completely optional but sensitive to the information structure of the sentence. The V2 structure is preferred when the subject is new information, while the V3 order is used when the subject is interpreted as given information. Furthermore, it will be shown that the two constructions are acquired (more or less) simultaneously by children growing up in this area, with the same patterns of information structure as for the adult language in place at a relatively early stage.

\section{ADULT SPEECH}

\subsection{The production of V2 and V3 word orders}

The data of adult speech discussed here is a sample of the adult production in the corpus. This sample consists of all $w h$-questions produced by the investigator (abbreviated INV in the examples) in ten of the files from one of the children, Ole.13-22. The reason why this sample was chosen is that the investigator in these ten files (who happens to be the author of this paper) speaks the Troms $\emptyset$ dialect, while the other adults in the study mainly speak other Northern dialects. No detailed study of the word order in these dialects has been carried out, and although it is likely that they are similar to the Troms $\varnothing$ dialect in this respect, it was decided to focus on what was clearly a sample of the Troms $\varnothing$ dialect in this initial investigation of the data. ${ }^{2}$ This work is part of a larger project, and an analysis of the data from the other adult speakers in the corpus will be carried out at a later stage. It should be noted that the corpus consists of spontaneous speech, and the recordings were not made with the structure of $w h$-questions in mind.

There are altogether exactly 300 main clause $w h$-questions in this small adult corpus, 182 with $k a$ 'what', 67 with kor 'where' and 51 with kem 'who'. In Table 1 


\begin{tabular}{lrrr}
\hline wh-word & \multicolumn{1}{l}{ V2 } & \multicolumn{1}{l}{ V3 } & \multicolumn{1}{l}{ Total } \\
\hline ka 'what' & $58(31.9 \%)$ & $124(68.1 \%)$ & $182(100 \%)$ \\
\hline kor 'where' & $38(56.7 \%)$ & $29(43.3 \%)$ & $67(100 \%)$ \\
\hline kem 'who' & $40(78.4 \%)$ & $11(21.6 \%)$ & $51(100 \%)$ \\
\hline Total & $136(45.3 \%)$ & $164(54.7 \%)$ & $300(100 \%)$ \\
\hline
\end{tabular}

Table 1. The number of occurrences of $\mathrm{V} 2$ and $\mathrm{V} 3$ word order in $w h$-questions in adult speech, INV in the files Ole.13-22.

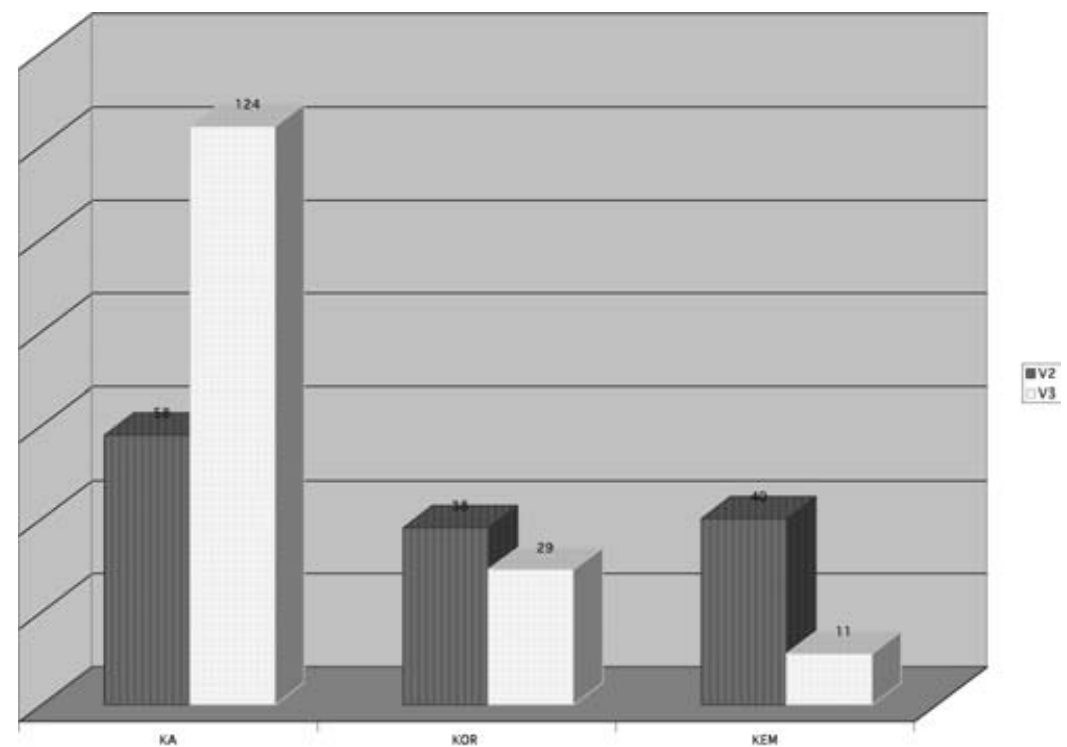

Figure 1. Number of occurrences of $\mathrm{V} 2$ and $\mathrm{V} 3$ word order in adult $\mathrm{ka}$-, $\mathrm{kor}$ - and $\mathrm{kem}$-questions ('what', 'where' and 'who'), INV in the files Ole.13-22.

the word order produced in these $w h$-questions is displayed, and it is clear that this adult speaker of the Troms $\varnothing$ dialect produces both word orders: V2 word order occurs in a little less than half of the sentences, $45.3 \%$, while the typical North Norwegian V3 order occurs in $54.7 \%$ of the examples. This order is more frequent after $k a$ than after the other two question words, especially kem. In Figure 1, the data in Table 1 are displayed as columns, providing a clearer illustration of this pattern.

\subsection{Verbs and subjects in V2 and V3 constructions}

A closer look at the data reveals certain patterns in the adult production concerning the preferred choice of verbs and subjects in the two constructions. Basically, the V2 order tends to occur when the subject is a full $\mathrm{DP}^{3}$ and the verb is a light verb (most 
often vare 'be'), while the V3 structure is preferred when the subject is a pronoun and the verb is not vare. Sentences (4) and (5) are typical examples of the V2 and V3 constructions:

(4) kor er pingvinen henne?

where is penguin-DEF LOC

'Where is the penguin?'

(INV, File Ole.16)

(5) kor du har fått det henne?

where you have got that LOC

'Where did you get that?'

(INV, File Ole.22)

In the following sections, the verbs and subjects involved in adult $\mathrm{kor}$-, $\mathrm{ka}$ - and kem-questions will be discussed in detail.

\subsubsection{Kor-questions ('where')}

As shown in Table 2, there are 38 examples with V2 and 29 examples with V3 word order with the question word kor in the adult corpus. In the $38 \mathrm{~V} 2$ examples, the verb is vare 'be' in every single case. The subject is a full DP in 33 cases $(86.8 \%)$ and a pronoun in only 5 cases $(13.2 \%)$. In the 29 examples with V3 order, the situation is reversed: in 24 cases $(82.8 \%)$, the verb is a lexical verb like komme 'come', si 'say' or tru 'believe', while in only 5 cases $(17.2 \%)$, the verb is vare. The subject is a pronoun in 26 cases $(89.7 \%)$ and a full DP in only 3 cases $(10.3 \%)$.

\begin{tabular}{|c|c|c|c|c|c|c|}
\hline & \multicolumn{3}{|l|}{ V2 } & \multicolumn{3}{|l|}{ V3 } \\
\hline & vare & Other V & Total & vare & Other V & Total \\
\hline Full DP & $33(86.8 \%)$ & 0 & 33 & 0 & 3 & $3(10.3 \%)$ \\
\hline Pronoun & $5(13.2 \%)$ & 0 & 5 & 5 & 21 & $26(89.7 \%)$ \\
\hline Total & $38(100 \%)$ & 0 & 38 & $5(17.2 \%)$ & $24(82.8 \%)$ & $29(100 \%)$ \\
\hline
\end{tabular}

Table 2. Subjects and verbs involved in adult kor-questions ('where') with V2 and V3 word order, INV in the files Ole.13-22.

The three V3 cases with a full DP subject all involve a verb other than vare, and the subject, although referred to by a full DP, seems to be familiar from the context, as in (6), for example, or mentioned in previous discourse, as in (7).

(6) kor sykebilen skal kjøre henne?

where ambulance-DEF shall drive $L O C$

'Where should the ambulance drive?'

(INV, File Ole.14; in a situation where the investigator and the child are playing with cars) 
(7) kor de pinnan kommer fra?

where those sticks come from

'Where do those sticks come from?'

(INV, File Ole.21; DP mentioned in previous sentence)

The five V3 cases with vare 'be' all occur with pronoun subjects (referring or expletive), as illustrated in (8) and (9).

(8) kor dem er henne?

where they are $\mathrm{LOC}$

'Where are they?'

(INV, File Ole.17; referring to shoes mentioned in previous sentence)

(9) kor det er rar lyd henne?

where it is strange sound LOC

'Where is the strange sound?'

(INV, File Ole.16)

\subsubsection{Ka-questions ('what')}

Table 3 shows that the situation with $k a$-questions is very similar to kor: in the 58 examples with V2 order, vare 'be' is still the most favored verb with 51 instances, while other verbs are preferred in the V3 structures, and pronoun subjects even more so.

\begin{tabular}{|c|c|c|c|c|c|c|}
\hline & \multicolumn{3}{|l|}{$\mathrm{V} 2$} & \multicolumn{3}{|l|}{ V3 } \\
\hline & vare & Other V & Total & vare & Other V & Total \\
\hline Full DP & $2(3.9 \%)$ & 5 & $7(12.1 \%)$ & 0 & $13(12.9 \%)$ & $13(10.5 \%)$ \\
\hline Pronoun & $49(96.1 \%)$ & 2 & $51(87.9 \%)$ & 23 & $88(87.1 \%)$ & $111(89.5 \%)$ \\
\hline Total & $51(87.9 \%)$ & $7(12.1 \%)$ & $58(100 \%)$ & $23(18.5 \%)$ & $101(81.5 \%)$ & $124(100 \%)$ \\
\hline
\end{tabular}

Table 3. Subjects and verbs involved in adult $\mathrm{ka}$-questions ('what') with V2 and V3 word order, INV in the files Ole.13-22.

The $124 k a$-questions with V3 word order seem to basically follow the same pattern as the questions with kor: as many as $101(81.5 \%)$ of those examples involve a verb other than vare, while vare occurs in 23 examples, making up only $18.5 \%$. Again, pronouns are much more frequent than full DPs, 111 (89.5\%) vs. 13 (10.5\%); a typical example is the sentence in (10).

(10) $\mathrm{ka} \mathrm{du}$ trur det er for nokka?

what you think that is for something

'What do you think that is?'

(INV, File Ole.16)

The pronouns are mostly personal pronouns like $d u$ 'you', han 'he', etc., referring to familiar people in the child's life or in the immediate context. All the thirteen 
examples with a full DP involve a verb other than vare, and all the DPs either refer to people familiar to the child, or things in the immediate situation, as in (11) and (12).

(11) ka ho mamma trudde? what DET mommie thought

'What did mommie think?'

(INV, File Ole.17)

(12) ka dragen gjør her?

what dragon-DEF does here

'What is the dragon doing here?'

(INV, File Ole.21; pointing to a dragon in a book)

This means that all the $23 \mathrm{~V} 3$ examples with vare 'be' occur with a pronoun subject (referring or expletive), as in (13) and (14).

(13) ka det er slags bil han har?

what it is kind-of car he has

'What kind of car does he have?'

(INV, File Ole.14)

(14) ka det er bilde av her?

what it is picture of here

'What is this a picture of?'

(INV, File Ole.13)

In the V2 constructions, on the other hand, there is a major difference between the kor-and $k a$-questions with respect to the choice of the subject: there are far more pronoun than full DP subjects in the $k a$-questions, 51 of the former compared to 7 of the latter, or $88 \%$ vs. $12 \%$. Corresponding figures for the V2 order with kor were exactly the opposite ( 5 to 33 , or $13.2 \%$ vs. $86.8 \%$ ). There is a clear pattern within the V2 forms with $k a$ though: most of the examples with a pronoun subject occur with vare, while most of the examples with other verbs occur with a full DP subject. Typical examples are thus (15) and especially (16); (16) occurs, with slight variations, as many as 35 times in the corpus.

(15) ka hete avdelinga di i barnehagen?

what is-called section your at daycare-DEF

'What is your section at daycare called?'

(INV, File Ole.13)

(16) ka er det (der) for noenting?

what is it there for something

'What is it/that?'

(INV, Files Ole.13-22; altogether 35 examples)

It is the 49 examples with vare and a pronoun subject (such as (16)) which are the ones that are somewhat unusual, as there is a pronoun subject in a V2 structure. In kor-questions, it is the V3 structure which is preferred when the subject is a pronoun (cf. section 2.2.1 above). The difference lies in the fact that the verb in all of these 
49 examples is vare, and although the subject is a pronoun, it is different from the personal pronouns which occur in the V3 constructions (see above): in almost all cases (47 instances) the subject is det 'it/that', and in the other two it is alt (det) 'all (that)'. That is, in most cases the subject seems to be a demonstrative pronoun, ${ }^{4}$ referring to something which has not been mentioned in previous discourse.

There are also ten examples in the corpus with the verb vare and the pronoun subject det, but with the opposite word order from what is found in (16):

(17) ka det er for noenting?

what it is for something

'What is it?'

(INV, Files Ole.13-22; altogether 10 examples)

A closer look reveals that these ten questions with V3 order seem to differ somewhat from the 35 with V2 word order: first of all, in half of these ten V3 examples, the subject is det her (lit. 'this here'), clearly referring to an item that is present in the context. Secondly, several of the V3 examples are somewhat special in that they are not always real questions. In sentence (18), for example, the situation seems to be that the investigator knows the answer and simply wants Ole to say it, while in (19) and (20), the adult seems to be producing some kind of repeated or embedded question: [Spфr du] ka det der er for nokka? '[Are you asking] what that is?'

(18) INV: er det en hund?

is it a dog

'Is it a dog?'

OLE: nei.

no

INV: ka det er for noenting? ${ }^{5}$

what it is for something

'What is it (then)?'

(File Ole.14)

(19) OLE: det der for nokka?

it there for something

'(What is) that?'

INV: ka det der er for nokka?

what it there is for something

'What is that?'

(File Ole.16)

(20) OLE: er det?

is that

'(What) is that?'

INV: ka det der er?

what it there is

'What is that?'

(File Ole.22) 


\subsubsection{Kem-questions ('who')}

The question word kem is the least frequent one in the data, with $40 \mathrm{~V} 2$ examples and only 11 sentences with V3 word order. ${ }^{6}$ As was the case with kor, the V2 examples all involve the verb vaere, and, as with $k a$, almost all those instances involve a pronoun. There are only three full DP subjects (7.5\%), pronoun subjects making up $92.5 \%$ of the examples. Again, the pronoun subjects are in all cases det 'it/that' and should probably be interpreted as demonstrative pronouns, as in example (21). In seven cases, the pronoun is followed by a relative clause introduced by som, which means that this is a so-called cleft subject question (see example (22)). The figures for kem are presented in Table 4.

(21) kem er det?

who is it

'Who is it/that?'

(INV, Files Ole.13-22; altogether 21 examples)

(22) kem er det som skal fiske?

who is it SOM shall fish

'Who is going to fish?'

(INV, File Ole.15)

\begin{tabular}{|c|c|c|c|c|c|c|}
\hline & \multicolumn{3}{|l|}{ V2 } & \multicolumn{3}{|l|}{ V3 } \\
\hline & vare & Other V & Total & vare & Other V & Total \\
\hline Full DP & $3(7.5 \%)$ & 0 & 3 & 0 & 0 & 0 \\
\hline Pronoun & $37(92.5 \%)$ & 0 & 37 & $3(27 \%)$ & $8(73 \%)$ & $11(100 \%)$ \\
\hline Total & $40(100 \%)$ & 0 & 40 & 3 & 8 & 11 \\
\hline
\end{tabular}

Table 4. Subjects and verbs involved in adult kem-questions ('who') with V2 and V3 word order, INV in the files Ole.13-22.

The 11 questions with $\mathrm{V} 3$ order mostly involve verbs other than vare (8 examples, $72 \%$ ), while vare occurs in 3 examples (27\%). There are no instances of full DP subjects; all 11 subjects are pronouns. But just as in the V3 examples with $k a$ above, many of these are different from the ones that occur in the V2 examples (det 'it/that'), as they are personal pronouns referring to people familiar from the context, as in (23) and (24).

(23) kem du bruke å leke med når du er i barnehagen? who you use to play with when you are at daycare-DEF 'Who do you normally play with when you are at daycare?'

(INV, File Ole.13) 
(24) kem dem treff no?

who they meet now

'Who are they meeting now?'

(INV, File Ole.17; referring to people in a picture in a book)

Only three of the examples involve det as an expletive subject, and these are (obviously) the three examples with vare. Actually, all of these seem to be different from the corresponding V2 questions in examples (21) and (22), which are to be interpreted as real information questions. When we consider the context, these three seem to be clarification questions, as seen, for example, in the questions given in bold in $(25)$ and (26). ${ }^{7}$

(25) OLE: < du får ikke kjøre.> [?] you get not drive

'You don't get to drive.'

INV: kem som ikkje får kjøre?

who SOM not get drive

'Who doesn't get to drive?'

OLE: det er ikke han mann får ikke kjøre.

it is not DEF man get not drive

'It is not the man who doesn't get to drive.'

INV: aha.

aha

INV: kem det er som skal kjøre?

who it is SOM shall drive

'Who is going to drive?'

OLE: $\mathrm{xx}$ får ikke kjøre.

get not drive

'xx doesn't get to drive.'

(File Ole.14)

(26) INV: ka det er jo bare $+/ /$ ?

what it is only

'What is it only ...?'

OLE: tante Kjerstin si bok

aunt Kjerstin POSS book

'Aunt Kjerstin's book'

INV: kem det er si bok?

who it is POSS book

'Whose book is it?'

(File Ole.18)

(The name Ole is pronouncing is difficult to understand - only later did the investigator find out what the name really was.) 


\subsection{Analysis of the adult data}

As illustrated by the examples in the previous section, the two word orders show clear differences regarding the preference of verbs and subjects used: in V2 constructions, the verb vare 'be' is extremely frequent and the subject is most often a full DP (in the kor-questions) or a demonstrative pronoun (in the $\mathrm{ka}$ - and $\mathrm{kem}$-questions), while the typical North Norwegian word order without verb movement (V3) is preferred when the subject is a (personal) pronoun and the verb is not vare.

A statistical analysis of the preference patterns for subject and verb types in the two word orders is difficult, as there are many empty cells in Tables $2-4$. When the figures in the three tables are summarized, creating a contingency table with only one empty cell, the assumptions of a loglinear model are satisfied. However, summarizing the figures in this way means that an important distinction is lost, namely the difference between kor-questions and questions with the other two question words with respect to subject type in the V2 constructions will disappear when the figures are simply collapsed. Additionally, the difference between pronoun types preferred in the two word orders (demonstratives with V2, personal pronouns with V3) will not be expressed. Nevertheless, a loglinear analysis of this new table indicates that there is a highly significant main effect for the variable subject (levels: full DP vs. pronoun) as well as a significant effect for type of verb (levels: vare vs. another verb), see Table 5. In addition, there is a highly significant interaction between word order and type of verb. There is, perhaps surprisingly, no statistically significant effect for the interaction between word order and type of subject, but this is possibly due to the restriction in the test mentioned above. However, there is a clear tendency for this effect $(\mathrm{p}<0.07)$.

\begin{tabular}{llcl}
\hline Effect name & df & Partial CHI-square & Probability \\
\hline Subject & 1 & 90.255 & 0.0001 \\
\hline Verb & 1 & 3.872 & 0.0419 \\
\hline V2/V3 vs. Verb & 1 & 166.188 & 0.0001 \\
\hline
\end{tabular}

Table 5. Loglinear analysis of the subject and verb types with $\mathrm{V} 2$ and $\mathrm{V} 3$ word order in the three types of WH-questions in the adult corpus.

As mentioned in the introduction, the optionality of the two word orders in the Troms $\varnothing$ dialect in grammaticality judgements has often been argued to be the result of the influence from the general V2 order of standard Norwegian, while V3 is the only order which is truly grammatical in the dialect (and therefore the only order which needs to be accounted for). The data in the present corpus are, of course, based on only one speaker, but as there is a lack of corpora of the Troms $\emptyset$ dialect, it will be assumed throughout the rest of this paper that the findings may be generalized 
to the dialect as a whole. And it seems unlikely that the figures and patterns found in this corpus are simply the result of dialect mixture: both word orders are used extensively, and the patterns are so clear that their use cannot be the result of random choices made by the speaker. It also seems obvious that the patterns under discussion are not constrained by any real syntactic restrictions. In every single example in the adult corpus, the sentence would still be grammatical if the subject and verb were put in the opposite order. What is going on in these constructions therefore seems to be related to the information structure of the sentence.

In the V3 structures, the subject is virtually always familiar or given information. This seems to be why a pronoun is often favored in this position, and when this position is filled by a full DP, it is always definite and familiar from the context. In fact, there seems to be a real syntactic definiteness constraint on this pre-verbal position, which is not found in the V2 structure, as shown in (27) and (28). ${ }^{8}$

*?Kor en blå brikke er?
where a blue piece is
'Where is a blue piece?'
Kor er en blå brikke?
where is a blue piece
'Where is a blue piece?'

Also, the verb vare 'be' is much preferred in the V2 constructions, especially with kor, where the subject is almost always a full DP. This verb is semantically so light that it will rarely contribute much information value itself, and thus it will almost always be the subject that provides the new information in the sentence. This is also the case in the $\mathrm{ka}$ - and $\mathrm{kem}$-questions, where the subject is often a pronoun in most cases a demonstrative pronoun which is the focus of the question. Typical examples, which abound in the data, are the following:

Kor er bamsen? [Full DP $=$ NEW]
where is teddy-DEF
'Where is the teddy?'

$\mathrm{Ka}$ du sir? [Pronoun $=$ GIVEN]
what you say
'What are you saying?'

The terms 'given' and 'new' information are used relatively informally here to refer to context, either situational or linguistic (previous mention). Given information could thus, to cite Chafe (1976:30), simply be defined as 'knowledge which the speaker assumes to be in the consciousness of the addressee at the time of the utterance'. It is possible that the given/new distinction also corresponds to a formal syntactic difference, where subjects occur in different positions in the clause 
depending on their information value. This idea is further developed in Westergaard \& Vangsnes (2002), but will not be pursued here.

The given/new distinction could then possibly explain why verb movement and hence V2 order is more frequent after kor 'where' than after $k a$ 'what' in this corpus: when asking a 'what'-question, one is often asking about something which is present (or given) in the immediate context, at least this seems to be the case in the type of discourse register used with (and by) children. A 'where'-question, on the other hand, often asks about something which is not present, either in the context or in the state of mind of the speaker(s). One especially revealing example is the following sequence of questions, highlighted, from the adult:

(31) OLE: xx mjau mjau sir pusekattan. meow meow say kitties-DEF 'xx meow, meow say the kitties.'

INV: ja.

yes

INV: <ka sir $>$ [/] ka sir hunden da? what says what says dog-DEF then

'What does the dog say then?'

OLE: voff voff. [Ole imitates a dog.]

INV: og eselet da \# ka det sir?

and donkey-DEF then what that says

'And the donkey then - what does that say?'

$\begin{array}{lll}\text { INV: } & \text { hanen } & \text { ja. } \\ & \text { rooster-DEF } & \text { yes }\end{array}$

'The rooster, yes.'

OLE: hanen \# og den + .

rooster-DEF \# and that

'The rooster - and that ...'

INV: ka hanen sir?

what rooster-DEF says

'What does the rooster say?'

(File Ole.17)

The first sentence in bold face is an example where the adult is introducing something new into the conversation (the dog), and thus a V2 structure is used. In the second bold-face sentence, a new element (the donkey) is introduced first, and then, once it is given information, it can be referred to by a pronoun - and put into pre-verbal position. The third example is different, in that the given information (the rooster) has been mentioned in the previous discourse, but is still referred to by a full DP. The 
pre-verbal position is nevertheless available for this element, because of its status as given information.

Thus, there seems to be a subtle semantic difference between a V2 structure and one with V3 order. In most cases, this difference can be simply attributed to the given vs. new information status of the subject, as in the above sentences ( $k a$ sir hunden [NEW]?/ka hanen [GIVEN] sir?). However, in some other cases, there seems to be a slightly more significant difference in meaning, related to presupposition: the V2 structure is most often a neutral information question, while the corresponding V3 structure seems to somehow presuppose the existence of something in the context, or simply be a clarification question (see the examples in section 2.2). In the following examples, I have tried to tease apart the difference between the V2 and V3 orders when the subject is a pronoun and the verb is vare in both constructions: ${ }^{9}$

$$
\begin{aligned}
& \text { a. Ka er det? } \\
& \text { what is it } \\
& \text { 'What is it/that?' (Tell me what that is, I don't know.) }
\end{aligned}
$$

b. Ka det er?

what it is

'What is it?' (I know there is something (going on), tell me about it.)

\section{a. Kem er det?} who is it

'Who is it/that?' (Tell me who that person is, I don't know.)

b. Kem det er?

who it is

'Who is it?' (Who is it, e.g. knocking on my door?)

Summing up, the choice of verbs and subjects involved in the V2 and V3 constructions as well as the interpretation of the various examples from the corpus in context strongly indicate that the choice between the two structures depends on the information value of the subject. The V2 construction is preferred when the subject is new information (often represented by a full DP), while the V3 construction is used when the subject is familiar in the context (often a pronoun), thus given information. This, of course, also corresponds to a well-known tendency in information structure, where old or given information is placed as early as possible in the sentence, while new (and often heavier) elements tend to occur towards the end.

\section{CHILD DATA}

\subsection{The production of V2 and V3 orders}

The corpus of child data consists of altogether 66 recorded one-hour sessions; 23 files with Ina (age 1;8.20-2;10.22), 21 files with Ann (age 1;8.20-3;0.1) and 22 files 


\begin{tabular}{|c|c|c|c|c|c|c|c|}
\hline \multirow[b]{2}{*}{$w h$-word } & \multicolumn{2}{|c|}{ INA $1 ; 8.20-2 ; 10.12$} & \multicolumn{2}{|c|}{ ANN $1 ; 8.20-3 ; 0.1$} & \multicolumn{2}{|c|}{ OLE $1 ; 9.10-2 ; 11.23$} & \multirow[b]{2}{*}{ Total } \\
\hline & $\mathrm{V} 2$ & V3 & $\mathrm{V} 2$ & V3 & $\mathrm{V} 2$ & V3 & \\
\hline $\begin{array}{l}k a \\
\text { 'what' }\end{array}$ & $\begin{array}{l}48 \\
(35 \%)\end{array}$ & $\begin{array}{l}89 \\
(65 \%)\end{array}$ & $\begin{array}{l}19 \\
(26.4 \%)\end{array}$ & $\begin{array}{l}53 \\
(73.6 \%)\end{array}$ & 1 & 0 & 210 \\
\hline $\begin{array}{l}\text { kor } \\
\text { 'where' }\end{array}$ & $\begin{array}{l}128 \\
(89.5 \%)\end{array}$ & $\begin{array}{l}15 \\
(10.5 \%)\end{array}$ & $\begin{array}{l}63 \\
(81 \%)\end{array}$ & $\begin{array}{l}15 \\
(19 \%)\end{array}$ & 42 & 0 & 263 \\
\hline $\begin{array}{l}\text { kem } \\
\text { 'who' }\end{array}$ & $\begin{array}{l}21 \\
(72.5 \%)\end{array}$ & $\begin{array}{l}8 \\
(27.5 \%)\end{array}$ & $\begin{array}{l}9 \\
(75 \%)\end{array}$ & $\begin{array}{l}3 \\
(25 \%)\end{array}$ & 3 & 0 & 44 \\
\hline Total & $\begin{array}{l}197 \\
(64 \%)\end{array}$ & $\begin{array}{c}112 \\
(36 \%)\end{array}$ & $\begin{array}{l}91 \\
(56 \%)\end{array}$ & $\begin{array}{l}71 \\
(44 \%)\end{array}$ & $\begin{array}{l}46 \\
(100 \%)\end{array}$ & 0 & 517 \\
\hline
\end{tabular}

Table 6. The total number of $w h$-questions with $\mathrm{V} 2$ and $\mathrm{V} 3$ word order in the corpus, for all three children.

with Ole (age 1;9.10-2;11.23). All sessions contain spontaneous speech in various play situations between the child and the investigator, and sometimes the parents. The children all live in Troms $\varnothing$, and all three have been in full-time daycare since the age of one; thus they have had extensive exposure to the Troms $\varnothing$ dialect. The children's parents all speak Northern dialects, which, as mentioned above, probably do not differ significantly from the Troms $\emptyset$ dialect with regard to the word order facts under consideration here.

In the introduction it was mentioned that if previous work on word order in the Troms $\varnothing$ dialect was right about adult speakers not producing V2 word order in questions with the monosyllabic wh-words, then it would be expected that the V3 order of the 'true' dialect would be learned first by children growing up in this area (disregarding possible orders of acquisition based on markedness and/or overgeneralizations, discussed in Westergaard, forthcoming). It was shown in the previous section that the one adult dialect speaker investigated in this study produces both word orders and, moreover, that the choice of V2 and V3 depends on the information structure of the sentence.

The three children in the study produce altogether 517 wh-questions with the monosyllabic question words ka, kor and kem ('what', 'where' and 'who'). The data are presented in Table 6, and the figures clearly show that both V2 and V3 structures are attested in child data before the age of three.

It is worth noting that the two girls produce overall more instances of V2 than V3, and Ole actually does not produce a single V3 structure as a full $w h$-question (but see below). However, he produces considerably fewer $w h$-questions than the girls on the whole, and the ones he does produce are mainly questions with the question word kor. These kor-questions also have a much larger proportion of V2 structures in 
the girls' production, while the $k a$-questions display a larger proportion of V3 word order.

In addition to regular $w h$-questions, all three children produce some non-targetlike $w h$-questions without question words, something which has also been attested and discussed for Swedish children by Santelmann (1995, 1997). This is the case especially in the early files, although these questions continue to be produced by the children long after they have started producing questions with $w h$-words. Wh-less questions will be discussed in more detail in section 3.3, but typical examples are the V2 construction in (34) and the structure without verb movement (V3) ${ }^{10}$ in (35), both of which are taken from the files of Ole. These show that even though this child does not produce a single V3 construction as a full wh-question, he DOES produce questions both with and without verb movement from a very early age.

(34) er doktoren?
is doctor-DEF

'(Where) is the doctor?'

(35) den gjør der?

that does there

'(What) is that doing there?'
(File Ole.2, age 1;10.0)

(File Ole.2, age $1 ; 10.0)$

Obviously, the number of different question types ( $\mathrm{ka}$, kor or $\mathrm{kem}$ ) produced by the individual children will vary with many non-linguistic factors, e.g. the personality of the child or the child's favorite activities during the recording sessions. However, for all the children in the study, the proportion of V2 vs. V3 structures does seem to follow a certain pattern, in that kor- and kem-questions trigger verb movement more often than $k a$-questions. This can be seen clearly in Figure 2, where the data in Table 6 are displayed as columns.

If we compare the graph in Figure 2 with that in Figure 1, which illustrates the adult's production, we see that there is a striking similarity between the child and adult data with respect to the proportions of V2 vs. V3 structures with the three question words, the latter word order being more common with the question word $k a$ 'what'. The only real difference is that the children seem to produce somewhat more V2 structures than the adult with the question word kor 'where'. This is illustrated in Figure 3, where the adult percentages for V2 and V3 order is compared with those of the two girls.

Another striking finding in the data is that there is no clear development from one word order to another, as might be expected given a markedness account of acquisition (see Westergaard, forthcoming). In the production of the two girls, where both word orders occur, both V2 and V3 orders are attested from the earliest files, for all question words. As an illustration of that, the graph in Figure 4 plots Ina's production of $k a$-questions ('what') across all the 23 files. 


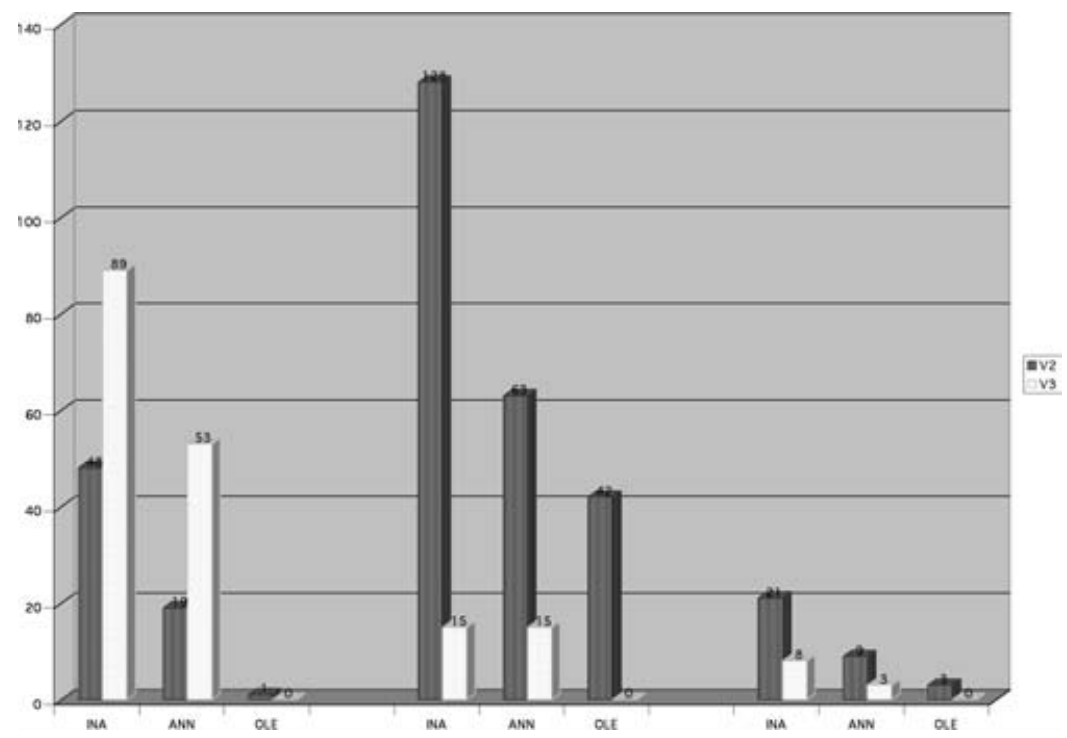

Figure 2. The number of occurrences in the three children's production of $\mathrm{V} 2$ and $\mathrm{V} 3$ word order in $k a$-questions ('what', first set of columns), kor-questions ('where', second set) and kem-questions ('who', third set).

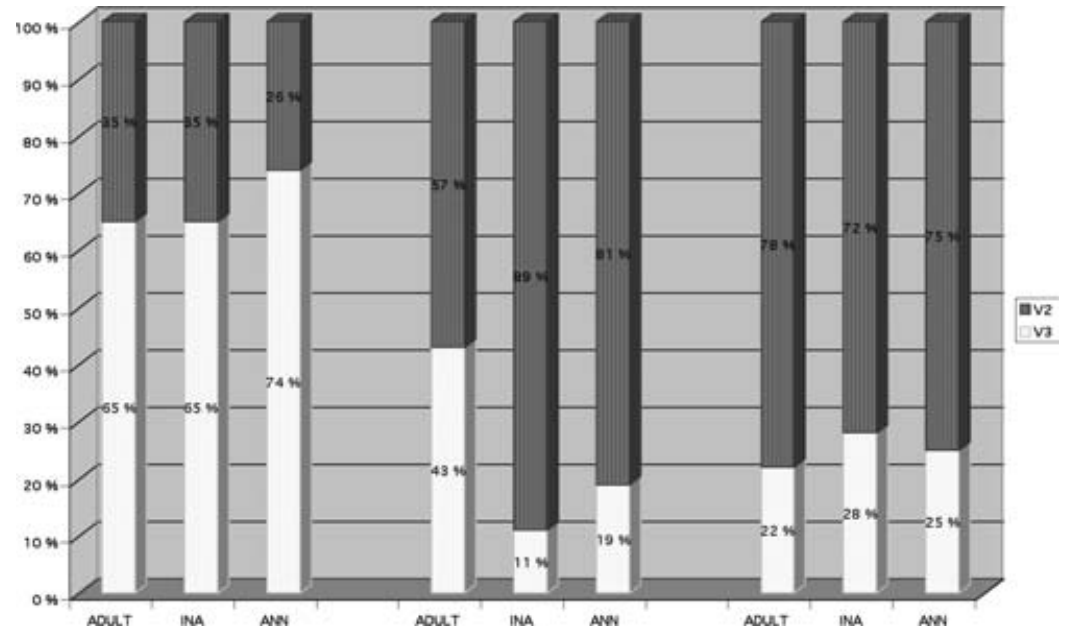

Figure 3. The percentage of $\mathrm{V} 2$ and $\mathrm{V} 3$ orders in the production of the adult and the two children Ina and Ann, in $k a$-questions ('what', first set of columns), kor-questions ('where', second set) and $\mathrm{kem}$-questions ('who', third set). 


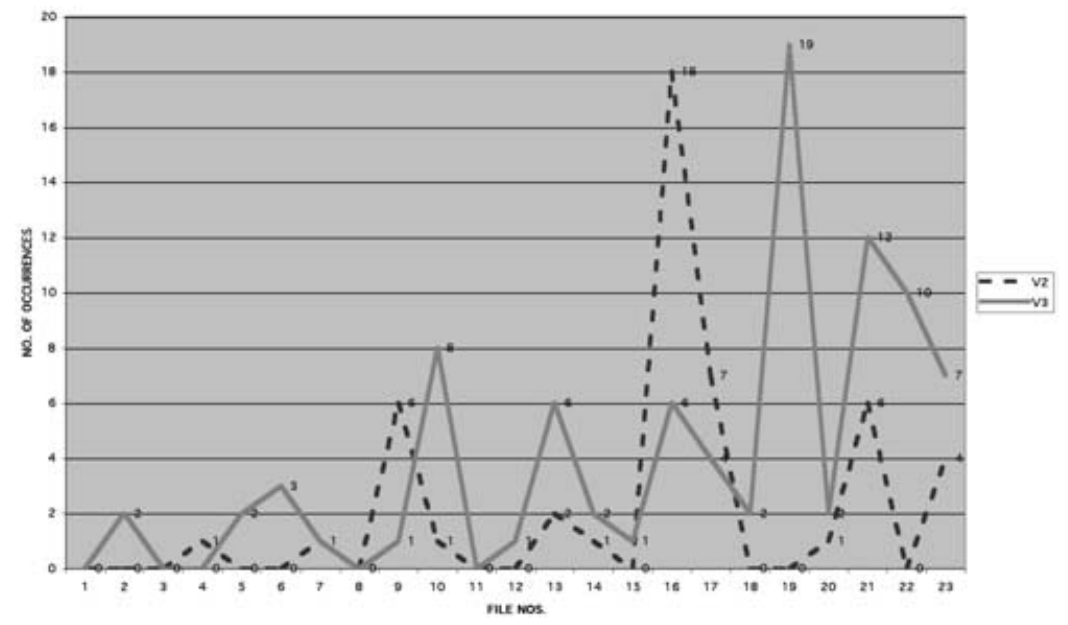

Figure 4. The number of $k a$-questions ('what') with V2 and V3 word order, Ina.1-23, age 1;8.20-2;10.12.

\subsection{Verbs and subjects involved in V2 and V3 constructions}

As illustrated in the previous section, the overall figures for V2 vs. V3 for the child corpus as a whole more or less parallels the adult figures. When we consider the distribution of subject and verb types preferred in the two constructions in the children's production, we find that that too is very similar to the adult preferences. Typical examples from Ina's files are given in (36) and (37), where the V2 structure occurs with a full DP subject and the verb vare 'be', while the V3 construction has another verb and a pronoun subject. This indicates that the distinction between the information value of the subject as given or new information is one that the children are sensitive to from their earliest production of $w h$-questions.

(36) ka du skal finne?

what you shall find

'What do you want to find?'

(37) kor er babyen?

(File Ina.5, age 2:0.5)

where is baby-DEF

'Where is the baby?'

(File Ina.6, age 2;1.0)

The following tables will illustrate this similarity only for the question word kor 'where'. ${ }^{11}$ Table 7 displays Ina's preference for subject and verb types in korquestions, where the overall distribution of V2 vs. V3 is $89.5 \%$ to $10.5 \%$. As we saw above, that means that Ina produces considerably more V2 structures than the adult (who also produced more V2 than V3 with kor, 56.7\% to 43.3\%). However, when the combination of subjects and verbs involved in these structures is considered, there is 


\begin{tabular}{|c|c|c|c|c|c|c|}
\hline & \multicolumn{3}{|l|}{$\mathrm{V} 2$} & \multicolumn{3}{|l|}{ V3 } \\
\hline & vare & Other V & Total & vare & Other V & Total \\
\hline Full DP & $115+2 ?(92.9 \%)$ & 0 & $115+2 ?(91.4 \%)$ & $1(14.3 \%)$ & $2(25 \%)$ & $3(20 \%)$ \\
\hline Pronoun & $9(7.1 \%)$ & 2 & $11(8.6 \%)$ & $6(85.7 \%)$ & $6(75 \%)$ & $12(80 \%)$ \\
\hline Total & $126(98.4 \%)$ & $2(1.6 \%)$ & $128(100 \%)$ & $7(46.7 \%)$ & $8(53.3 \%)$ & $15(100 \%)$ \\
\hline
\end{tabular}

Table 7. Subjects and verbs in kor-questions ('where') with V2 and V3 order, in the files Ina.1-23, age $1 ; 8.20-2 ; 10.12$.

\begin{tabular}{|c|c|c|c|c|c|c|}
\hline & \multicolumn{3}{|l|}{$\mathrm{V} 2$} & \multicolumn{3}{|l|}{ V3 } \\
\hline & vare & Other V & Total & vare & Other V & Total \\
\hline Full DP & $48(78.7 \%)$ & 0 & $48(76.2 \%)$ & $2(40 \%)$ & $2(20 \%)$ & $4(26.7 \%)$ \\
\hline Pronoun & $13(21.3 \%)$ & 2 & $15(23.8 \%)$ & $3(60 \%)$ & $8(80 \%)$ & $11(73.3 \%)$ \\
\hline Total & $61(96.8 \%)$ & $2(3.2 \%)$ & $63(100 \%)$ & $5(33.3 \%)$ & $10(67.7 \%)$ & $15(100 \%)$ \\
\hline
\end{tabular}

Table 8. Subjects and verbs in kor-questions ('where') with V2 and V3 order, in the files Ann.121, age $1 ; 8.20-3 ; 0.1$.

no serious discrepancy in the adult and child patterns. Basically, Ina just produces more instances of one pattern, namely questions with a full DP subject and the verb vare (altogether 117 examples or $92.9 \%$ of all V2 constructions), which would be V2 also in the adult system. ${ }^{12}$

Ann produces fewer wh-questions overall than Ina, but the distribution of V2 vs. V3, or the verbs and subject types involved in the respective constructions, does not differ significantly from Ina's figures or those of the adult. Table 8 displays the distribution of subject and verb types involved in Ann's kor-questions. Again, we see a preference for full DP subjects and the verb vare in the V2 structures, and pronoun subjects and other verbs in the V3 constructions.

Finally, let us consider the child Ole, who differs from the other two in that he does not produce a single V3 structure as a full $w h$-question in the corpus, with any of the three $w h$-words. He produces considerably fewer questions than the two girls, a total of only 46 full $w h$-questions in the whole corpus, compared, for example, to Ina's 309. However, a closer investigation of the distribution of subjects and verbs, displayed in Table 9, reveals that Ole does not seem to exhibit a completely different behavior from the other two children. He simply produces fewer patterns than they do, basically just one: questions with the question word kor, with the verb vare and a full DP subject, i.e. the pattern that is also used more by the other two children, especially Ina. 


\begin{tabular}{|c|c|c|c|c|c|c|}
\hline & \multicolumn{2}{|c|}{$k a$ 'what' } & \multicolumn{2}{|l|}{ kor 'where' } & \multicolumn{2}{|c|}{ kem 'who' } \\
\hline & vare & Other v & vare & Other V & vare & Other V \\
\hline Full DP & 0 & 0 & $37(92.5 \%)$ & 0 & 0 & 0 \\
\hline Pronoun & 1 & 0 & $3(7.5 \%)$ & 2 & 3 & 0 \\
\hline Total & 1 & 0 & $40(100 \%)$ & 2 & 3 & 0 \\
\hline
\end{tabular}

Table 9. Subjects and verbs in $w h$-questions - all with V2 order, in the files Ole.1-22, age 1;9.10-2;11.23.

The figures in Tables 7-9 show that the children produce more or less the same patterns for subject and verb types with the two word orders as the adult. Thus, apart from possibly a slight preference for $\mathrm{V} 2$ in the child data, it seems difficult to detect ANY development in these children with regard to word order in these constructions, as wh-questions with verb movement (V2) as well as those without (V3) are attested from the earliest files of all three children (when Ole's wh-less questions are taken into account). Even though the number of sentences produced within each pattern may differ, the patterns themselves are stable across all four individuals. Thus, it is possible to argue that not only do the children acquire the two word orders more or less simultaneously, but they also seem to be aware of the subtle distinction in information structure between the two orders from their earliest production of $w h$-questions.

However, the behavior of Ole, who does not produce any V3 structures as a full wh-question in the corpus, suggests that $\mathrm{V} 3$ word order may be in place slightly later than the V2 order, which correponds to the word order required in all other main clauses in the language (including the Troms $\varnothing$ dialect). A closer look at the children's $w h$-less questions in the next section will also reveal something about their development in this respect, and will be shown to support a hypothesis of V2-before-V3.

\subsection{Questions without wh-words}

As mentioned above, all the children produce some questions without wh-words, illustrated by examples (34) and (35) from the files of Ole, repeated here for convenience.

(34) er doktoren?
is doctor-DEF

(V2: vare + full DP)

'(Where) is the doctor?'

(File Ole.2, age $1 ; 10.0$ )
den gjør der?
(V3: Pronoun + other V)
that does there

'(What) is that doing there?'

(File Ole.2, age 1;10.0) 


\begin{tabular}{|c|c|c|c|c|c|c|}
\hline \multirow[b]{2}{*}{$w h$-word } & \multicolumn{2}{|c|}{ INA $1 ; 8.20-2 ; 10.12$} & \multicolumn{2}{|c|}{ ANN $1 ; 8.20-3 ; 0.1$} & \multicolumn{2}{|c|}{ OLE $1 ; 9.10-2 ; 11.23$} \\
\hline & $\mathrm{V} 2$ & V3 & $\mathrm{V} 2$ & V3 & $\mathrm{V} 2$ & V3 \\
\hline$k a$ 'what' & $1(+5 ?)$ & 117 & 0 & 0 & $1(+15 ?)$ & 11 \\
\hline kor 'where' & $0(+2 ?)$ & 6 & 0 & 2 & $3(+6 ?)$ & 2 \\
\hline Total & $1(+7 ?)$ & 123 & 0 & 2 & $4(+21 ?)$ & 13 \\
\hline
\end{tabular}

Table 10. The total number of $w h$-less questions with $\mathrm{V} 2$ and $\mathrm{V} 3$ word order in the corpus, for all three children.

The first striking feature of these questions is that the same word order patterns seem to be in place with respect to the choice of subjects and verb types preferred, even when the wh-word, which is supposed to trigger the special V3 order, is not expressed. Thus, the V2 structure in (34) has the verb vare and a full DP subject, while the structure without verb movement in (35) has a pronoun subject and another verb than vare. No complete overview of the subject and verb types in wh-less questions will be given here, but as an illustration of the pattern it can be noted that out of Ina's 117 instances of V3 questions with the question word $k a$ 'what' (see Table 10), 105 have the typical pattern of a pronoun subject and a verb other than vare.

Another interesting feature emerges when the number of V2 vs. V3 structures in the children's $w h$-less questions is considered. While there is a slight preference for V2 in the children's production of full wh-questions, there is a considerably larger number of V3 constructions in the questions without $w$-words, as shown in Table $10 .^{13}$

Concentrating only on the production of Ina, we see that there are as many as 123 wh-less questions with V3, while there are only 6 (and in fact, possibly just one; see footnote 13) with V2 order. The V2 structures all occur in the earliest files, while the V3 questions are distributed (more or less evenly) over the 23 files, as illustrated in Figure 5. Corresponding numbers for Ina's questions with $w h$-words (from Table 6) are 197 with V2 to 112 with V3.

This seems to support the developmental hypothesis of V2-before-V3, as these figures indicate that the $w h$-questions without verb movement are in place slightly later in their full form than the ones with verb movement: the V2 structures occur with all three elements expressed ( $w h$-word, verb and subject) at an earlier stage than the V3 constructions. That is, verb movement itself does not seem to be hard for these children, as both structures are present in their earliest files either as a full or a reduced $w h$-question. But this suggests that there is something else about the SYNTAX of the V3 structure which is more difficult than the V2 construction, since it takes longer to occur in its full form. This could also explain the behavior 


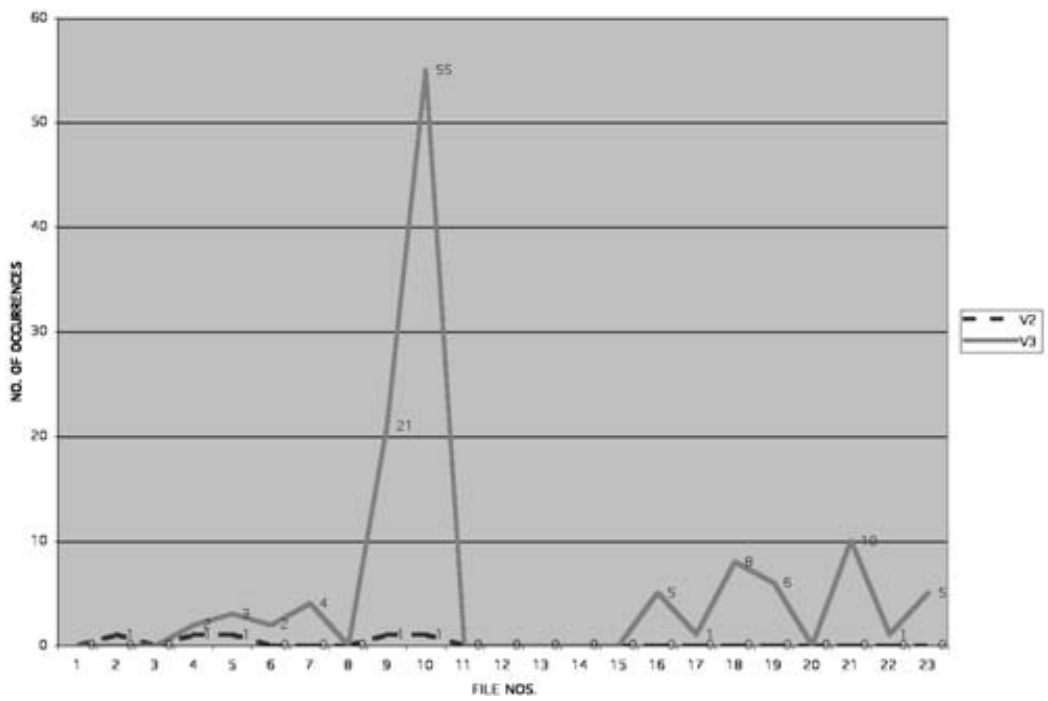

Figure 5. The number of occurrences of $\mathrm{V} 2$ and $\mathrm{V} 3$ word order in $w h$-less questions in the files Ina.1-23, age 1;8.20-2;10.12.

of Ole, who only produces V2 structures as full wh-questions. Although he does produce questions without verb movement, he is not yet at a stage where he is able to include all the necessary elements (wh-word, subject and verb) in these constructions.

A further interesting feature of the data emerges upon a detailed investigation of Ina's wh-less questions in the two files which have the largest number of these constructions. These are files 9 and 10, when Ina is 2;2.12 and 2;3.12, respectively. In file 9, Ina produces $21 \mathrm{~V} 3$ structures and in file 10 as many as 55, all with the verb hete 'is-called'. In the same two files, there is only one example in each of a V2 question without a $w h$-word (but several full V2 questions). ${ }^{14}$ Typical examples are sentences like (38); the only V2 example in file 9 is given in (39). Note, by the way, that the given/new distinction is in place, indicated by the pronoun subjects in all the V3 structures, and the full DP subject in the only V2 structure. In the same two files, there are also many wh-questions with hete, where the wh-word is in place, but the subject is missing, as in sentence (40). ${ }^{15}$

(38) den/ han/ho hete?

that/he/ she is-called

'(What) is that/he/she called?'

(21 examples in File Ina.9, age 2;2.12)

(39) E hete farga? ${ }^{16}$

$P A R T$ is-called color- $D E F$

'(What) is the color called?'

(File Ina.9, age 2;2.12) 
(40) ka hete?

what is-called

'What is (it) called?'

(17 examples in File Ina.9, age 2;2.12)

Again, these data seem to indicate that the V3 structure is somehow more difficult to acquire than the V2 structure. When the overall complexity of the sentence is too demanding for the child, then some kind of bottleneck mechanism may come into play, and EITHER the $w h$-word OR the subject is deleted. Obviously, it cannot be stated with certainty that these subjectless sentences are 'underlyingly' structures without verb movement, as there is no overt material that the verb has moved across. However, given the situation in which these questions were uttered (the child asking about things in the immediate context) and assuming that it is more likely that the subject will be deleted when it is given information, it is the V3 structure that would be expected here. It is also striking that this bottleneck mechanism does not seem to occur to the same extent in the constructions which require V2 word order: in those questions both the $w h$-word and the subject are in place earlier than in the V3 structures.

\section{DISCUSSION}

In this section, I would like to speculate on what a possible syntactic analysis could be of the two constructions and what such an analysis would need to take into consideration. Taraldsen (1986) proposed an account of the V3 construction where the monosyllabic $w h$-words behave like heads and move into $\mathrm{C}$, thus preventing the verb from moving to this position. Radford (1992) suggested a similar analysis for early child English, to explain why some children seem to go through a stage where they invert in yes-no questions, but not in wh-questions.

However, this study has shown that the V2 construction is also produced in wh-questions by dialect speakers, and given the patterns found in both the adult and the child corpus, this word order also seems to be part of the language system. Thus, an analysis of the word order in $w h$-questions in the Troms $\varnothing$ dialect must take both structures into consideration. Furthermore, the syntactic analysis of the two constructions must take into account the different interpretations of the two word orders, and verb movement must somehow be blocked only when the subject is interpreted as given information (in V3 constructions). In V2 structures, on the other hand, the $w h$-word should move to SpecCP and the verb to $\mathrm{C}$, as in standard analyses of V2 questions. This would account for the V2 structure being acquired slightly earlier than $\mathrm{V} 3$, as it would be the result of a process that is seen in every other main clause in the language.

Despite the clear preferences for subject and verb types in the V2 and V3 constructions, there seems to be no choice of subject or verb that makes either 
structure truly ungrammatical. The only real restriction on the V3 construction is on the $w h$-word: it may only have one syllable $(\mathrm{ka}, \mathrm{kor}, \mathrm{kem})$ and it may not be stressed, as shown in (41).

$$
\begin{aligned}
& \text { *KOR du bor? vs. KOR bor du? } \\
& \text { where you live where live you } \\
& \text { 'WHERE do you live?' }
\end{aligned}
$$

It is thus likely that it is the short $w h$-words that undergo an unusual syntactic process in the V3 construction. This could be some kind of cliticization or movement to C (as suggested by Taraldsen 1986), so that these wh-phrases could be said to behave like heads or clitics. That would then partly explain why this word order is only possible with the monosyllabic $w h$-words: this process is blocked for $w h$ elements like korfor 'why' and korsen 'how' because they are simply too heavy to behave like heads. Although the details of such an analysis are still unclear, what is important is that it is the V3 construction that would be somehow special and unusual, in that it allows a structure that is otherwise not available in the language.

Another relevant fact that must be considered in a syntactic analysis of the word order of $w h$-questions is that in V3 structures, the verb does not seem to move at all, but needs to stay inside the VP, as is shown by its position in relation to the adverbial and the negative ikkje 'not' in (42) and (43).

(42) Ka han egentlig [vp sir]?

what he really says

'What is he really saying?'

(43) Kor ho ikkje [vp vil gå]?
where she not will go

'Where doesn't she want to go?'

As word order is related to the information value of the subject, it seems reasonable to propose that there are two different subject positions in the clause, one for new information, and a higher one for given or old information. Obvious candidates are SpecAgrSP for given information and the lower SpecTP for new information. This is the proposal in Westergaard \& Vangsnes (2002), where an attempt is made to explain the behavior of the different $w h$-words in relation to the verb in terms of the split-CP analysis of Rizzi (1997). Briefly, this analysis follows Taraldsen's (1986) idea that monosyllabic wh-words are heads and merged in Force, thus obviating V-to-Force movement. However, a new subject in SpecTP involves a relation with a focus operator in the specifier of another left peripheral head, Foc, which then attracts the verb to the $\mathrm{CP}$ domain, thus yielding V2 order in some wh-questions. 
In a markedness account of verb movement, V2 is commonly considered to be a marked word order. Within the minimalist framework, movement is triggered by strong features and according to Roberts (1999), for example, any movement is thus by definition always marked. Platzack (1996) assumes that children start out with what he calls the IHS, the initial hypothesis of syntax, and he argues that they should initially assume that all features are weak, and only later learn which features are strong in their language by exposure to positive evidence in the input. On this account, the V3 construction of the Troms $\varnothing$ dialect would be considered unmarked, as there is no verb movement, and the V2 word order would thus be predicted to be acquired slightly later.

Another possible definition of markedness can be found in Henry \& Tangney (1999). According to their definition, a language which has consistent movement in all sentence types is simpler, or less marked, than a language which only has movement in some sentence types. This means that it is not sufficient to look at one particular feature in isolation (e.g. verb movement); it must be considered within the language system that it occurs in. Norwegian, which is assumed to have verb movement to $\mathrm{C}$ in all main clauses, can thus be argued to be LESS complex than English, which only has auxiliary movement to $\mathrm{C}$ in questions. Henry \& Tangney also argue that a complex grammar will only be acquired if the crucial constructions have a certain frequency in the input, in first as well as in second language acquisition. Any feature which adds complexity to a grammar should thus be a relatively late acquisition and vulnerable to change. On this account, it would be the V $3 w h$-questions in the Troms $\emptyset$ dialect which are unusual or marked, in that they are different from all other main clauses in the language, which do have verb movement and V2 order.

The data investigated in this paper provide some evidence that the full V3 construction is acquired slightly later than V2 in wh-questions, and this indicates that it is the V3 structure that is more complex syntactically. This seems to correspond more closely to the Henry \& Tangney account of markedness, as it would be the V3 construction that is considered unusual (and thus marked). It should be noted that this cannot simply be because the V3 sentences do not have verb movement. ${ }^{17}$ It could be because verb movement is blocked by another special mechanism in the language, namely the behavior of the monosyllabic $w h$-words.

There are still many unanswered questions and in order to gain a true understanding of word order in $w h$-questions in the Troms $\emptyset$ dialect, further research is needed, both on the possible syntactic relationships with other constructions in the language, as well as on larger corpora of both adult and child speakers of the dialect.

\section{SUMMARY AND CONCLUSION}

In this paper I have argued that V2 structures in questions with the monosyllabic wh-words ka, kor and kem ('what', 'where' and 'who') as well as the ones with 
V3 order, are part of the Troms $\emptyset$ dialect of Norwegian. The choice between the two structures is dependent on the information structure of the sentence, more specifically on the status of the subject as given or new information. The V3 structure is used if the subject is given information, the V2 structure if the subject is interpreted as new information.

The children in this study seem to be aware of the given/new distinction from the earliest files, and wh-questions with verb movement occur at the same time as questions without verb movement in the children's production. However, the behavior of one of the children in the study (who only produces V2 as full $w h$-questions) as well as the considerable number of $w h$-less questions without verb movement, suggests that the syntax of the V3 structure is somewhat harder to learn. This is not necessarily because movement is less marked than non-movement, but probably because there is another marked process, the behavior of the monosyllabic wh-words, which blocks movement in this case. The V3 construction may, therefore, be acquired slightly later than the V2 structure, which should be the result of a regular process of verb movement which is seen in every other main clause in the language. This would support an analysis of the V3 structure in the Troms $\varnothing$ dialect as the result of a marked syntactic process.

\section{ACKNOWLEDGEMENTS}

An earlier version of this paper was presented at the 19th Scandinavian Conference of Linguistics at the University of Troms $\varnothing$ in January 2002, and I am grateful to participants at the Language Acquisition Workshop for helpful comments. Thanks also to Anders Holmberg, Peter Svenonius, Tarald Taraldsen, Øystein Alexander Vangsnes, the editor Sten Vikner and three anonymous $N J L$ reviewers for valuable suggestions.

\section{NOTES}

1. The question of possible orders of acquisition is discussed in Westergaard (forthcoming) in terms of the notions of markedness and overgeneralizations.

2. There are dialects of Norwegian which differ from the Troms $\varnothing$ dialect in that there is no $\mathrm{V} 2$ requirement in any type of $w h$-question, i.e. where even V3 sentences like those in (1) would be grammatical. This has been attested for the Northern dialect of Nordreisa by Nilsen (1996) and for various Western dialects by e.g. Åfarli $(1985,1986)$.

3. The term 'full DP' will be used to refer to DPs which have an NP complement, e.g. bamsen 'the teddy' or den nye lareren 'the new teacher', in order to distinguish them from pronouns.

4. The demonstrative pronoun in Norwegian is identical to the personal pronoun det 'it' as well as the expletive and it is, therefore, not always clear in the corpus what is meant. 
5. The question words $k a$ 'what' and kor 'where' are often followed by the expressions for noenting/for nokka and hen/henne, respectively (the latter is glossed as LOC in this article). In child language, these expressions often occur without the question words, as in (19), for example.

6. Only sentences with kem which are not subject questions have been included here. Subject questions, of which there are only 7 examples with $\mathrm{kem}$ and 23 examples with $\mathrm{ka}$ in the corpus, are different in that they require the insertion of the relative complementizer som in second position in Northern dialects, which parallels what happens in embedded clauses in Standard Norwegian:

(i) Kem som kom?

(Troms $\emptyset$ dialect)

who SOM came

'Who came?'

(ii) Så du hvem som kom? (Standard Norwegian)

saw you who SOM came

'Did you see who came?'

7. In these examples and in (31) below, standard CHAT notation is used. Thus xx means an unintelligible word, \# signifies a pause, $+/$ means interruption, while $+/ /$ ? is the symbol for a self-interrupted question. In addition, [/] means repetition and [?] means that the transcriber was unsure of what was said. The last two symbols refer to an immediately preceding word or material within angled brackets. Most of the data in this paper need not be annotated in this way.

8. In questions with an indefinite subject, an expletive construction would be preferred, and then either order would be grammatical:

(i) Kor er det en blå brikke?/Kor det er en blå brikke? where is it a blue piece where it is a blue piece

'Where is there a blue piece?'

9. The distinctions in meaning/presupposition are subtle and complicated by the fact that they change with intonation. Thus, the V2 sentences in (32a) and (33a) with emphatic stress on the verb seem to mean the same as the $b$. versions.

10. When the $w h$-word is missing, the verb is of course in first position when the verb has moved and in second when verb movement has not applied. However, the constructions will still be called V2 and V3, respectively.

11. A more detailed overview, which includes the other question words, can be found in Westergaard (forthcoming).

12. The figure 2 followed by a question mark in the V2 part of Table 7 refers to two instances where the transcriber has not been able to identify what the child said. In these cases, exemplified in (i), it is likely that the xx's refer to a noun rather than a pronoun in these cases.

(i) Kor er $\mathrm{xx}$ ?

where is

13. The figures in parentheses refer to examples in the corpus which are unclear, as they all start with a form pronounced [e:]. This could either be the present form of the verb vare 'be', $e r$, or a question particle $\mathrm{E}$ (and has been transcribed sometimes as $e r$ and sometimes 
as $\mathrm{E}$ in the corpus). Question particles like this have also been attested for Swedish by Santelmann (1997). The presence of examples like (i) in Ole's files, where there is both E/er as well as another verb, suggests that at least in his production, [e:] should be analyzed as a particle:

(i) E/er den hete?

$P A R T /$ is that is-called

'(What) is that is called?'

(File Ole.8, age 2;2.12)

14. The number of full $w h$-questions with $\mathrm{V} 2$ in the two files is 9 and 18 respectively, while the corresponding figures for full $w h$-questions with $\mathrm{V} 3$ are 8 and 1.

15. The subjectless sentences seem to be counterevidence to a common argument in the literature that children do not omit subjects in $w h$-questions in non-pro-drop languages (see e.g. Rizzi 1994, 2000).

16. Note that this example may not even be a true $w h$-less question, as the question particle $\mathrm{E}$ is present, which may be used in place of the wh-word.

17. If that were the case, then verb movement would always be considered to be less marked than non-movement, and children should thus be expected to transfer the V2 order learned for main clauses to embedded clauses. In the later files, the three children produce a few embedded questions (altogether 46), but not a single one occurs with V2 word order.

\section{REFERENCES}

Åfarli, Tor. 1985. Absence of V2 effects in a dialect of Norwegian. In Östen Dahl \& Anders Holmberg (eds.), Working Papers in Scandinavian Syntax 22, 1-21, University of Stockholm.

Åfarli, Tor. 1986. Some syntactic structures in a dialect of Norwegian. Working Papers in Linguistics 3, 93-111, University of Trondheim.

Chafe, Wallace L. 1976. Givenness, contrastiveness, definiteness, subjects, topics, and point of view. In Charles N. Li (ed.), Subject and Topic. New York: Academic Press, 27-55.

Henry, Alison \& Denise Tangney 1999. Functional categories and parameter setting in the second-language acquisition of Irish in early childhood. In Michel DeGraff (ed.), Language Creation and Language Change: Creolization, Diachrony and Development. Cambridge, MA: MIT Press, 239-253.

Nilsen, Hilde. 1996. Koff $\phi r$ dem sir det? [Why do they say that?] Candidata philologiae thesis, University of Troms $\emptyset$.

Nordgård, Torbjørn. 1985. Word Order, Binding and the Empty Category Principle. Candidatus philologiae thesis, University of Trondheim.

Platzack, Christer. 1996. The initial hypothesis of syntax: A minimalist perspective on language acquisition and attrition. In Harald Clahsen (ed.), Generative Perspectives on Language Acquisition: Empirical Findings, Theoretical Considerations, Crosslinguistic Comparisons. Amsterdam: John Benjamins, 369-414.

Radford, Andrew. 1992. The acquisition of the morphosyntax of finite verbs in English. In Jürgen Meisel (ed.), The Acquisition of Verb Placement. Dordrecht: Kluwer, 23-62.

Rice, Curt \& Peter Svenonius 1998. Prosodic V2 in Northern Norwegian. Ms., University of Troms $\varnothing$. 
Rizzi, Luigi. 1994. Early null subjects. In Teun Hoekstra \& Bonnie Schwartz (eds.), Language Acquisition Studies in Generative Grammar. Amsterdam \& Philadelphia: John Benjamins, 151-196.

Rizzi, Luigi. 1997. The fine structure of the left periphery. In Liliane Haegeman (ed.), Elements of Grammar: Handbook of Generative Syntax. Dordrecht: Kluwer, 281-337.

Rizzi, Luigi. 2000. Remarks on early null subjects. In Marc-Ariel Friedeman \& Luigi Rizzi (eds.), The Acquisition of Syntax. London: Longman, 269-292.

Roberts, Ian. 1999. Verb movement and markedness. In Michel DeGraff (ed.), Language Creation and Language Change: Creolization, Diachrony and Development. Cambridge, MA: MIT Press, 287-327.

Santelmann, Lynn. 1995. The Acquisition of Verb Second Grammar in Child Swedish: Continuity of Universal Grammar in Wh-questions, Topicalizations and Verb Raising. Ph.D dissertation, Cornell University.

Santelmann, Lynn. 1997. Wh-less questions in early Swedish: An argument for continuity, CP and operators. In Shamitha Someshakar, Kyoko Yamakoshi, Maria Blume \& Claire Foley (eds.), Cornell Working Papers in Linguistics 15, 217-253.

Taraldsen, Knut Tarald. 1986. On verb second and the functional content of syntactic categories. In Hubert Haider \& Martin Prinzhorn (eds.), Verb Second Phenomena in Germanic Languages. Dordrecht: Foris, 7-25.

Vikner, Sten. 1995. Verb Movement and Expletive Subjects in the Germanic Languages. New York \& Oxford: Oxford University Press.

Westergaard, Marit Richardsen. Forthcoming. On the acquisition of word order in $w h$-questions in the Troms $\varnothing$ dialect. In Peter Svenonius, Anne Dahl \& Marit Richardsen Westergaard (eds.), Nordlyd 31.3: Proceedings of the 19th Scandinavian Conference of Linguistics. University of Tromsø.

Westergaard, Marit Richardsen \& Øystein Alexander Vangsnes. 2002. Wh-questions, V2, and the left periphery of three Norwegian dialects. Ms., University of Troms $\emptyset$. (To appear in Journal of Comparative Germanic Linguistics.) 